\title{
Séveso solicitude
}

\author{
Alastair Hay visits Séveso and finds \\ political as well as technical problems
}

\begin{abstract}
TT IS ten months since the ICMESA chemical plant reactor exploded discharging tetrachlorodibenzo- $p$-dioxin (dioxin) over a large section of the Italian town of Séveso. Though considerable progress in the reclamation of the largest residential portion of the area is now apparent, the record of success has not extended to actual physical destruction of the dioxin present in the contaminated material collected. Vacillation over the methods to be adopted is caused by several factors: a paucity of relevant scientific data, hostility by Séveso residents to some of the methods which the Lombardy regional government has proposed, and indecision in government circles at the regional and national level. At regional level the preferred course of action seems to be destruction by incineration, but Séveso residents view construction of the incinerator with alarm and this could prove electorally damaging to the political parties concerned.
\end{abstract}

Professor Augusto Giovanardi, coordinator of the Decontamination Commission appointed by the Lombardy regional government to supervise operations at Séveso, says that according to measurements made by the commission between 300 and 500 grams of dioxin were deposited in the most contaminated area (designated zone $A$ ) and that some 10 grams were present in the less affected zone $B$. He dismisses the suggestion made by a British scientist, Dr Donald Lee, that up to $130 \mathrm{~kg}$ of dioxin could have been produced in the reactor explosion. However, Giovanardi acknowledges that neither his commission nor Givaudan had been given permission by the Italian courts to check the reactor contents. This analysis was being carried out solely by scientists employed by the judiciary.

\section{Seven sections}

For the purpose of decontamination policy zone $\mathrm{A}$ has been divided into seven sections. Areas A1-A3-those nearest the reactor-are the most seriously contaminated, and contain about $80 \%$ of the discharged dioxin. $\mathrm{A} 4$ and A5 are areas of 'medium contamination'; $\mathrm{A} 6$ and $\mathrm{A} 7$, the least affected portions of zone $A$, housed $80 \%$ of the residents evacuated from the area by the local authority. Consequently it has been sections A6 and A7 which have received most attention by the authorities. Giovanardi explains that buildings in the area have been decontaminated by a process of vacuum cleaning and washing with solvents. "Most of the soil and vegetation from the area had been stripped away two weeks ago", he says, "and the pavements and roads will be the last portions to be cleared". He adds: "We hope that the people with homes in the area will be able to return to them sometime in the months of June to August this year".

Concurrent with the decontamination work in zone $A$ the commission has been working in zone $\mathbf{B}$, which may yet have to be expanded. Here the residents have been asked to abide by certain rules to minimise personal exposure to dioxin. Children leave the area for the daylight hours, and women in the first trimester of pregnancy are advised to move from the district until the foetus is at least three months of age. With the work on sections A6 and $\mathrm{A} 7$ now nearing completion Giovanardi says the commission "is now applying the same operation to the houses, vegetable gardens and so on in zone $\mathrm{B}$ that we have used in $\mathrm{A} 6$ and $A 7^{\prime \prime}$. Contaminated soil and vegetation from these areas is being deposited in the 'medium contaminated' sections A4 and A5. The vegetation is to be incinerated, but the soil may well be left unprocessed in the hope that microbial degradation will reduce the dioxin concentrations to acceptable levels.

Whereas the consensus of scientific opinion is that the soil should be removed from zones $\mathrm{A} 6$ and $\mathrm{A} 7$ and definitely from the 'heavily contaminated' areas $\mathrm{A} 1-\mathrm{A} 3$, opinions differ on the methods to be applied to degrade the dioxin present. Incineration is apparently the approach favoured on theoretical grounds by some members of the commission, but this view is by no means universal. Other scientists are conducting trials on photochemical decomposition of dioxin, solvent extraction of the chemical (from the soil) and degradation by steam distillation.

The most vehement opposition to the incineration proposal and to the plans to construct an incinerator on the site of the ICMESA plant comes from the Séveso residents. They have had enough. If the incinerator has to be built, they argue that it should be built somewhere else. They know that incineration of the soil on the scale proposed will be an enormous under-

\section{Sorry, for copyright reasons some images on this page may not be available online}

\section{峁}

Barrier to progress?

taking. It will be an untried process and they claim that they are to be the 'guinea pigs' of the regional authority. In the past month they have mounted a demonstration in Milan to protest against the incinerator's construction and gunmen have broken into the office of the health officer at Séveso, shooting him several times in the legs.

Information relevant to the handling of dioxin-contaminated soil has been procured for the Italian authorities by Professor Barry Commoner from the US Department of Defense. On a visit to Italy in February and March, Commoner expressed concern and disappointment at the measures being adopted. He wrote that it was evident that "a systematic examination of alternatives [for degrading dioxin] has not been carried out" by the Decontamination Commission, and much of the decontamination work was "unnecessarily confused". Asked about Commoner's criticisms, Giovanardi's response is that whereas incineration appears to be the most feasible degradative process, his commission is considering all alternative procedures.

\section{Government Commission}

Last year the Italian Government appointed its own Commission to assist the local authorities at Séveso and the regional government in Lombardy. The Under Secretary of State for Health, Dr Fernando Russo, is the commission's president. As such he has the responsibility for collating all the available information on dioxin both nationally and internationally. He says there is "no evidence available on the complete destruction of dioxin. We are still searching for this evidence on an international scale".

Russo says that the final aim of all the authorities is to reduce the dioxin 
levels to zero. The Ministry of Health convened a meeting in Rome recently to assess the situation at which a whole series of programmes were discussed. Many problems remained unsolved. Séveso has been a very bitter lesson for Italy. It has forced the government to review its legislation on industrial hazards, pollution control, toxicology and food additives, amongst other things. The message has been rammed home that 'prevention is better than cure'. Russo says Italy would like legislation on pollution control in particular to be a European Community measure, for national legislation on this issue "might provoke reprisals" and force multinational companies to go elsewhere.

As for the specific pollution problem at Séveso, Russo is in no doubt that ICMESA's owners Givaudan, as a big company, "will more or less have to pay" for the damage they caused, estimated now to cost 113 billion liraabout $£ 80$ million. Givaudan states that this figure seems "extremely large".

Just to ensure that they do receive payment, the local authorities in and around Séveso, the Lombardy regional government and the central government are all involved in litigation for damages against Givaudan. The company, they claim, had inadequate safety features operating in the trichlorophenol reactor. And to compound the problem, when the accident occurred the ICMESA management provided insufficient information on the pollution hazard. As a result many people were put to unnecessary risk by their exposure to dioxin for the two weeks before residents were evacuated.

\section{Central matter}

This two week period of exposure is central to the health problems of the Séveso population and to the issue of

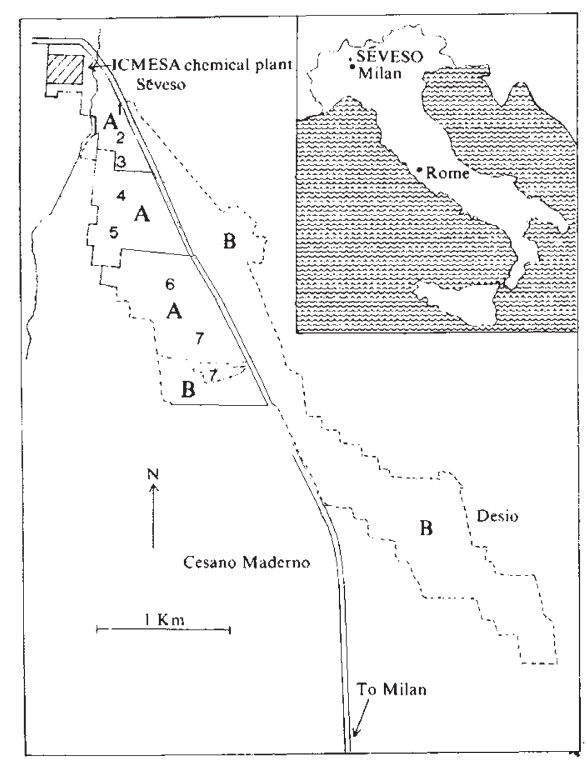

abortion for the pregnant women exposed to dioxin. Although Russo claims that the Italian government wasn't against abortion for these women and that the opposition came from local doctors at Séveso, he has the impression that it hadn't been too difficult for the women to procure legal terminations.

This impression is not confirmed by Ms Adele Faccio, the Radical Party Member of Parliament for the constituency of Genoa. She was in the Séveso area in July and August last year and, as a result, has been particularly concerned about the question of abortions for the Séveso women.

"It was extremely difficult for these women to obtain legal terminations", she declares emphatically. To substantiate her claim she cites the figures for the abortions performed on the women. "Only 30 women had legal terminations", she says, "whereas twice this number have had illegal abortions. The illegal terminations were performed by 'women's self-help groups' for cases where the foetus was not older than ten weeks. For women in a more advanced state of pregnancy it was essential to send them abroad for an abortion".

But if legal abortions have proved difficult for the Séveso women, there is some relief in Italian medical circles over the results of the examinations performed on the foetuses from those women permitted legal terminations. These examinations were conducted by Professor Alfred Gropp and $\mathrm{Dr}$ Helga Rehder of the Lubeck Medical School, Germany, and Professor Francesco Céfis and Dr Laura Sanchioni of the Istituti Clinici di Perfezionamento in Milan. Of the 34 foetuses examined only one showed any signs of abnormal development. As with most of the foetuses examined, however, this one embryo was badly macerated-a common situation with induced abortions.

The results must therefore be interpreted with great caution. They could be suggestive in this one instance of foetal Down's syndrome. This, however, is a not uncommon foetal abnormality in most populations. Some UK clinicians think it is unlikely to be due to dioxin. Professor Gropp and his colleagues claim in a report to the Lombardy Regional Health Authority that "the results of the embryo-morphological studies do not give any hint for damage brought about by the action of exogenous agents (dioxin)". They add the rider, however, that the negative result must not necessarily mean that dioxin "does not bear a risk for the mother and foetus". The examinations had certain inherent limitations: minor malformations and particularly organ damage are not detectable in the very young foetus; only a limited number of cases could be studied, and most of these embryos were incomplete and of different gestational age.

Professor Gaetano Fara, chairman of the Lombardy region's Health and Epidemiology Commission for Séveso, adds a further qualification to the interpretation of these results. He admits the foetal examinations cannot be interpreted in the context of a true epidemiological survey; they are an analysis of data to hand. He adds that, for a true epidemiological survey, the population would obviously have been much larger and more carefully monitored.

As for the eight children from the Séveso area born with abnormalities, Fara claims that statistics would indicate that this incidence of malformation is no greater than the average for the region. Some epidemiologists in the UK have expressed the opinion that because of the variation in the pattern malformations reported at Séveso it is quite possible that they are not due to dioxin. They add that, if the chemical was responsible for these abnormalities it would be reasonable to expect a more consistent pattern in the defects observed.

Even though some of the medical results appear to be reassuring, Fara insists that they still consider the Séveso residents to be a 'population at risk'. He said that a preliminary report on the children from Séveso based on three visits to doctors had revealed no immunological damage in this group, compared with their peers in a non-contaminated area. Similarly chromosomal studies performed on the 34 aborted foetuses by Dr Luigi de Carli at the University of Bazia had revealed no genetical deviations from the accepted norm.

But Fara does admit that the cases of chloracne reported represent an area greater than that officially designated as being contaminated. He acknowledges that it is worrying, but adds that of the 525 cases of reported chloracne, only 1 in 4 were confirmed on subsequent re-examination. In view of the toxicity of dioxin, however, the regional authority is to embark on a large scale epidemiological study of the area. Fara says that the population will have to be monitored for years to come.

If Professor Giovanardi's predictions are correct the Decontamination Commission will not complete its programme to bring dioxin down to an acceptable level before 1980. By this time most of the residents will have returned to their homes, but as a population still 'at risk' fears about dioxin will still be a part of their lives. 